\title{
PSP07
}

\section{Comments on Application of Passive Seismic Methods in Turkey}

N. Karakurt* (Turkey Energy Strategies Politics Research Center) \& O. Akyener (Turkey Energy Strategies Politics Research Center)

\section{SUMMARY}

This study aims to evaluate passive seismic opportunities in Turkey and availability of certain locations for passive seismic applications. Our conceptualapproach includesanalyzing seismic activities in Turkey, current upstream market trends, and if Turkish companies can find economical aspects of passive seismic beneficial. 
Recording seismic events produced by earthquakes is a cost-effective techniquecomparing to traditional seismic data acquisition techniques there require launching heavy equipment, such as vibro-trucks or dynamite in and around due locations. The number of earthquakes plays a key role for an efficient passive seismic operation. The more earthquakes mean the better seismic resolution since each quake increases the fold.It also gives an advantage to make changes in the geometry for the geophone locations. Velocity cubes calculated by passive seismic seem to produce correct velocity distribution in the ground even if complex fault structures are present, where conventional seismic data acquisition might fail. Passive seismic velocity cubes might come in handy to characterize complexly faultedareas; they even might be applied in data processing sequences to improve conventional seismic data resolution.

Several companies worldwide apply'Passive Seismic Tomography' in oil and gas exploration. However, currently there is no passive seismic usage in oil and gas explorations in Turkey. This new technology/technique can be brought to Turkish explorers' attention because there are a number of active complex fault systems that trigger too many earthquakes in Turkey. Another reason is that Turkey spends a lot of money (1500 to $2000 \mathrm{~km} 2 \mathrm{D}$ lines and $2000 \mathrm{~km} 2$ 3D per year) to discover oil and gas fields but seismic resolution in conventional methodology over faulted areas is slightly poor. Passive seismic can handle these ambiguities and can help to better define small reservoirs that Turkey struggling with.

This study aims to evaluate passive seismic opportunities in Turkey and availability of certain locations for passive seismic applications. Our conceptualapproach includesanalyzing seismic activities in Turkey, current upstream market trends, and if Turkish companies can find economical aspects of passive seismic beneficial. 